\title{
Investigation of colloidal biogenic sulfur flocculation: Optimization using response
}

surface analysis

Fan Chen ${ }^{1}$, Ye Yuan ${ }^{1}$, Chuan Chen ${ }^{1}$, Youkang Zhao ${ }^{1}$, Wenbo Tan ${ }^{1}$, Cong Huang ${ }^{1}$, Xijun $\mathrm{Xu}^{1}$, Aijie Wang ${ }^{1,2, *}$

1. State Key Laboratory of Urban Water Resource and Environment, Harbin Institute of Technology, Harbin 150090, China. E-mail: chenfanhit@163.com

2. Key Laboratory of Environmental Biotechnology, Research Center for Eco-Environmental Sciences, Chinese Academy of Sciences, China

Received 07 May 2015

Revised 31 July 2015

Accepted 03 August 2015

Abstract: The colloidal properties of biogenic elemental sulfur $\left(\mathrm{S}^{0}\right)$ cause solid-liquid separation problems, such as poor settling and membrane fouling. In this study, the separation of $\mathrm{S}^{0}$ from bulk liquids was performed using flocculation. Polyaluminum chloride (PAC), polyacrylamide (PAM) and microbial flocculant (MBF) were compared to investigate their abilities to flocculate $S^{0}$ produced during the treatment of sulfate-containing wastewater. A novel approach with response surface methodology (RSM) was employed to evaluate the effects and interactions of flocculant dose, $\mathrm{pH}$ and stirring intensity, on the treatment efficiency in terms of the $S^{0}$ flocculation and the supernatant turbidity removal. The dose optimization results indicated that the $S^{0}$ flocculation efficiency decreased in the following order PAC > MBF > PAM. Optimum $\mathrm{S}^{0}$ flocculation conditions were observed at $\mathrm{pH} 4.73$, a stirring speed of $129 \mathrm{r} / \mathrm{min}$ and a flocculant dose of $2.42 \mathrm{mg}$ PAC/mg S. During optimum flocculation conditions, the $\mathrm{S}^{0}$ flocculation rate reached 97.53\%. Confirmation experiments demonstrated that employing PAC for $S^{0}$ flocculation is feasible and RSM is an efficient approach for optimizing the process of $\mathrm{S}^{0}$ flocculation. The results provide basic parameters and conditions for recovering sulfur during the treatment of sulfate-laden wastewaters. 
Keywords: Elemental sulfur; Flocculation; Optimization; Response surface methodology (RSM)

*Corresponding author: E-mail: ajwang @ rcees.ac.cn (Aijie Wang)

\section{Introduction}

Sulfate-laden wastewaters are produced by pharmaceutical enterprises, pulp and paper manufacturers, petrochemical plants, mineral processes and acid mine drainage resulting from mining activities (Knobel and Lewis, 2002). In anaerobic environments, sulfate can be converted into sulfide, such as $\mathrm{H}_{2} \mathrm{~S}$, which is corrosive to metals and toxic to living species (Celis-Garcia et al., 2008). Biological processes for treating sulfate-laden wastewater mainly include two processes, the reduction of sulfate to sulfide by sulfate-reducing bacteria and the oxidation of sulfide to sulfur $\left(S^{0}\right)$ by sulfide oxidation bacteria (Wang et al., 2005). Yuan et al. (2014a) developed an integrated reactor system for the simultaneous removal of COD, sulfate and ammonium (Integrated C-S-N removal system).

The $\mathrm{S}^{0}$ reclaimed from sulfate-laden wastewaters can be recovered as a renewable resource for sulfuric acid production, fertilizer industries, and as a substrate for bioleaching processes (Celis-Garcia et al., 2008). $S^{0}$-containing effluents are stable suspensions containing biogenic sulfur colloids that are either largely associated with biomass or cannot be isolated from the suspension because their particle size is too small (Schlegel, 1989; Janssen et al., 1994; Sahinkaya et al., 2011; Yuan et al., 2014b). However, the excessive accumulation of biogenic sulfur without efficient isolation may result in pipe blockage (Beristain-Cardoso et al., 2008; Fortuny et al., 2010) and secondary pollution (Hao et al., 2006). Thus, a highly effective biogenic sulfur isolation step is essential for the successful application of the biological process.

Many researchers have studied biogenic sulfur isolation processes based on the surface characteristics and aggregation of biogenic sulfur (Yuan et al., 2014b; Janssen et 
al., 1994; Li et al., 2000, 2006). For example, Li et al. (2000) used the sand filtration-extraction-distillation process and Paques (Holland) developed an air flotation process to separate biogenic sulfur (Cao et al., 2002). In comparison with separation processes such as filtration, extraction and flotation, the plain sedimentation of sulfur particles is the cheapest and most attractive method (Janssen et al., 1996), while flocculation and sedimentation can achieve more efficient biogenic sulfur separation (Yuan et al., 2014b).

In the flocculation process, the efficiency is governed by various factors, such as the type and dosage of flocculant, $\mathrm{pH}$, mixing speed and time, temperature and retention time (Wang et al., 2011). A proper optimization of these factors could significantly increase its treatment efficiency. Response surface methodology (RSM) is an efficient way to achieve such an optimization by analyzing and modeling the effects of multiple variables and their responses and finally optimizing the process. This method has been widely used for the optimization of various processes in food chemistry, material science, chemical engineering and biotechnology (Wang et al., 2011). Córdova et al. (2011), Kiran and Thanasekaran (2011), and Özer et al. (2008) studied the biosorption of lead, copper and nickel on Aspergillus terreus, Lyngbya putealis and Enteromorpha prolifera, respectively, using response surface methodology. Zheng et al. (2014) investigated the optimization of the flocculation process using RSM for diethyl phthalate removal with anionic polyacrylamide. Jadhav and Mahajan (2014) successfully applied RSM in water/wastewater treatment using Coccinia indica and found that RSM is a highly effective tool for optimizing the flocculation process.

The main objective of this work was to separate $S^{0}$ using the flocculation process, which was optimized using RSM. Removal efficiencies of both $S^{0}$ and supernatant turbidity were chosen as the dependent output variables. The novel optimization strategy used for $\mathrm{S}^{0}$ flocculation in this study is expected to provide basic parameters and conditions for recovering sulfur during the treatment of sulfate-laden wastewaters. 


\section{Materials and methods}

\subsection{Integrated C-S-N removal system and effluent}

The integrated C-S-N removal system modified from Yuan et al. (2014a) was used to produce $\mathrm{S}^{0}$-containing effluent. The plexiglass expanded granular sludge blanket reactor was a modified version of the reactor developed by Chen et al. (2008). The reactor was kept at $30 \pm 1{ }^{\circ} \mathrm{C}$. The compositions of the medium and the micronutrients were described by Yuan et al. (2014a). An internally circulating fluid with reflux ratio of 6:1 was used to suspend granules in the reactor. Adding $1.6 \mathrm{~kg} \mathrm{TOC} /\left(\mathrm{m}^{3} \cdot\right.$ day $), 1 \mathrm{~kg}$ $\mathrm{SO}_{4}{ }^{2-} /\left(\mathrm{m}^{3} \cdot\right.$ day $)$, and $0.6 \mathrm{~kg} \mathrm{~N} /\left(\mathrm{m}^{3} \cdot\right.$ day $)$, respectively, resulted in nearly complete conversion of sulfate, nitrate and TOC to $\mathrm{S}^{0}, \mathrm{~N}_{2}$ and $\mathrm{CO}_{2}$. The effluent from the denitrifying sulfide removal unit (Fig. 1) was a milky white suspension with a turbidity of $350 \pm 25$ nephelometric turbidity units (NTU) and a pH of $9.80 \pm 0.20$. The zeta potentials of the suspended particles in the $S^{0}$-containing effluent were $-19.6 \pm 1.4 \mathrm{mV}$, and the $S^{0}$ concentration was between 100 and $120 \mathrm{mg} / \mathrm{L}$.

\subsection{Preparation of flocculant}

Flocculants are classified as inorganic flocculants, such as polyaluminum chloride (PAC), synthetic organic flocculants, such as polyacrylamide (PAM) derivatives, and natural occurring flocculants, such as microbial flocculant (MBF) and chitosan (Bezawada et al., 2013; Prazeres et al., 2013; Riaño and García-González, 2014). Chemical flocculants are commonly used in water and wastewater treatment industries because of their cost-effectiveness and efficient flocculation abilities (More et al., 2014). Bioflocculants have attracted research and industry interest as alternative flocculants due to their high flocculation performance, ecofriendliness, and biodegradability (Aljuboori et al., 2013, 2014; Bezawada et al., 2013). Therefore, PAC, PAM and MBF were chosen in this study. Moreover, because biogenic sulfur colloids carry a negative charge, cationic 
polyacrylamide was used to separate biogenic sulfur. PAC and PAM, purchased from Tianjin Chemical Reagent Co., China, were of analytical reagent grade and used without further purification. MBF was produced by the mixed culture of F2 and F6 with the proportion of $1: 1$ at the following fermentation conditions: fermentation time of $24 \mathrm{hr}$, temperature of $30^{\circ} \mathrm{C}$, rotation speed of $150 \mathrm{r} / \mathrm{min}$ (Zhu et al., 2006). Strain F2 and F6 are Bacillus sp..

\subsection{Batch flocculation studies}

Batch flocculation experiments were performed in $500 \mathrm{~mL}$ beakers containing 300 $\mathrm{mL} \mathrm{S}^{0}$-containing effluent mixed with known flocculant doses. In a preliminary study, experiments were initiated to determine narrower ranges of flocculant dose, $\mathrm{pH}$ and stirring intensity before designing the experimental runs. According to the results of the preliminary experiments for different flocculant, there were significant effects on $S^{0}$ flocculation when the dose, $\mathrm{pH}$ and stirring intensity changed from 1.3 to $3.3 \mathrm{mg}$ flocculant/mg S, 3 to 9 and 80 to 160 r/min, respectively. Next, dose optimization batch experiments were performed at $25^{\circ} \mathrm{C}$ with rapid mixing (300 r/min, $3 \mathrm{~min}$ ), and then slow mixing (120 r/min, $10 \mathrm{~min}$ ) with 1.3-3.3 $\mathrm{mg}$ flocculant/mg S was performed to determine the optimum dose. Then, the suspension was allowed to settle freely for another $30 \mathrm{~min}$. Suspension samples at $2 \mathrm{~cm}$ below the water surface were collected to analyze their turbidity and sulfur contents. Coagulation tests with no flocculants were used as controls. Next, the interactions of $\mathrm{pH}$ (ranging 3-9) and mixing speed (ranging 80-160 r/min) on the flocculating rate were investigated. The slow mixing rate changed when the effect of the mixing speed was considered. The $\mathrm{pH}$ of each solution was initially adjusted using 1 and $0.1 \mathrm{~mol} / \mathrm{L} \mathrm{HCl}$ and $\mathrm{NaOH}$ solutions to reach the required $\mathrm{pH}$ value before adding the flocculant. All of the experiments were performed in triplicate, and their mean values are reported. The biogenic sulfur flocculation rate $(\theta, \%)$ was calculated according to the following Eq. (1): 


$$
\theta=\left(A_{0}-A_{1}\right) / A_{0} \times 100 \%
$$

where, $A_{0}(\mathrm{mg} / \mathrm{L})$ is the total biogenic $\mathrm{S}^{0}$ concentration in the effluent of denitrifying sulfide removal unit and $A_{1}(\mathrm{mg} / \mathrm{L})$ is the $S^{0}$ concentration in the supernatant after flocculation.

\subsection{Experimental design and optimization}

The effects of operating parameters were optimized using RSM. Design Expert (version 8.0.1, Stat-Ease, Inc., MN) software was used for statistical data analysis. RSM represents independent process variables using the following quantitative equation:

$$
Y=f\left(A_{1}, A_{2}, A_{3}, \ldots \ldots, A_{n}\right)
$$

where, $Y$ is the biogenic sulfur flocculation rate; $f$ is the response function, and $A_{1}, A_{2}$, $A_{3}, . ., A_{n}$ are independent variables.

The response surface is obtained by plotting the expected response; however, the value of $f$ is unknown and can be very complicated. A quadratic model that includes the linear model used to predict the response variable and explore the design surface is shown below (Eq. (3)).

$$
Y=b_{0}+\sum_{j=1}^{k} b_{j} A_{j}+\sum_{j=1}^{k} b_{j j} A_{j}^{2}+\sum_{i} \sum_{<j=2}^{k} b_{i j} A_{i} A_{j}+\varepsilon
$$

where, $Y$ is the biogenic $S^{0}$ flocculation rate, $A_{i}$ and $A_{j}$ are variables, $b_{0}$ is the constant coefficient, $b_{j}, b_{j j}$ and $b_{i j}$ are interaction coefficients of the linear, quadratic and second order terms, respectively, and $\varepsilon$ is the error.

In this study, central composite design (CCD) was used for RSM in the experimental design, which is well suited for fitting a quadratic surface and usually works well for process optimization. In this study, one factor design using 5 levels for a quadratic model was used to evaluate the effects of flocculant dose on $\mathrm{S}^{0}$ flocculation (Table 1). $\mathrm{pH}$ and stirring intensity of $S^{0}$ flocculation were studied using the CCD model with two levels (the minimum and the maximum) when the optimum dose was determined. The 
experimental factor levels used in the factorial design are described in Table 2. In the experimental design model, $\mathrm{pH}$ (3-9) and stirring intensity (80-160 r/min) were used as input variables. In addition, the biogenic $S^{0}$ flocculation rate was used as the response of the system. The experimental design matrix derived from the CCD model and the results is shown in Table 3 .

The quality of the polynomial model fit was expressed using the regression

coefficient $\left(R^{2}\right)$ and $R_{\text {adj }}{ }^{2}$. The statistical significance was checked using an adequate precision ratio and the $F$-test.

\subsection{Analysis methods}

The collected liquor samples were passed through $0.45 \mu \mathrm{m}$ filters before measuring the sulfate and thiosulfate concentrations using an ion chromatograph (ICS-3000, Dionex, USA) equipped with a conductivity detector and an Ion-Pac AG4A AS4A-SC 4 mm analytical column. Elemental sulfur in the Integrated C-S-N removal system effluent was measured using the sulfite method (Jiang et al., 2009). A JJ-3A six digital electric mixer was used to stir the solution.

\section{Results and discussion}

\subsection{Effect of flocculant dose on biogenic $S^{0}$ flocculation}

\subsubsection{RSM one-factor designs and results}

The flocculant dose was varied from 1.3 to $3.3 \mathrm{mg}$ flocculant $/ \mathrm{mg} \mathrm{S}$, while the other parameters were held constant (temperature $25^{\circ} \mathrm{C}$, rapid mixing (300 r/min, $3 \mathrm{~min}$ ), slow mixing (120 r/min, $10 \mathrm{~min})$ and $\mathrm{pH}$ 5). The experimental designs and results are shown in Table 1.

The $\mathrm{S}^{0}$ flocculation and turbidity removal curves were fitted using multiple regressions in Design Expert 8.0.1 based on the experimental value and the RSM one-factor predicted value (Fig. 2). It is important to determine whether fitted curving 
adequately approximates real values. Graphical and numerical methods are primarily used to validate the models (Jadhav and Mahajan, 2014). In this case, the $R^{2}$ value of the biogenic $\mathrm{S}^{0}$ flocculation curves (PAC, 0.9943; PAM, 0.9671; MBF, 0.9963) and the turbidity removal curves (PAC, 0.9994; PAM, 0.9433; MBF, 0.9741) only indicate that $5.67 \%-0.06 \%$ of the total variation is not explained by these curves. The $R_{\mathrm{adj}}{ }^{2}$ values of the biogenic $S^{0}$ flocculation curves (PAC, 0.9829; PAM, 0.9506; MBF, 0.9925) and turbidity removal curves (PAC, 0.9829; PAM, 0.8866; MBF, 0.9481) are high enough to indicate that these fitting curves were highly significant. Fig. 3 is the normal probability plot for $\mathrm{S}^{0}$ flocculation and confirms that the assumptions of normality were satisfied for the experimental data. Adequate precision can be used to measure the signal to noise ratio, and a ratio greater than 4 is considered desirable. Therefore, the ratios of the biogenic $S^{0}$ flocculation capacity (PAC, 23.81; PAM, 15.76; MBF, 34.78) and turbidity removal (PAC, 71.12; PAM, 10.23; MBF, 13.60) indicate adequate signals for the models used to navigate the design space.

\subsubsection{Biogenic $S^{0}$ flocculation and turbidity removal analysis}

The effects of flocculant dose on the $S^{0}$ flocculation rate by PAC, PAM and MBF are shown in Fig. 2, which also shows that PAC and MBF were more effective than PAM for $S^{0}$ flocculation. The $S^{0}$ flocculation capacity of PAC increased up to $2.30-2.80 \mathrm{mg}$ $\mathrm{PAC} / \mathrm{mg} \mathrm{S}$, and the $\mathrm{S}^{0}$ flocculation rate reached $81 \%-86 \%$ before decreasing as the PAC dose increased. The $\mathrm{S}^{0}$ flocculation capacity of PAM gradually increased to $13 \%-14 \%$ as the PAM dose increased to 2.3-2.8 $\mathrm{mg}$ PAM/mg S, and then remained relatively constant. Compared with PAC and PAM, the effects of the MBF dose on the $\mathrm{S}^{0}$ flocculation rate were obviously different. The $S^{0}$ flocculation rate rapidly increased from 1.3 to $1.8 \mathrm{mg}$ $\mathrm{MBF} / \mathrm{mg} \mathrm{S}$ before gradually increasing as the $\mathrm{MBF}$ dose increased to $2.3-2.8 \mathrm{mg}$ $\mathrm{MBF} / \mathrm{mg} \mathrm{S}$, reaching a flocculation rate of $75 \%-76 \% \mathrm{~S}^{0}$. Above 2.3-2.8 mg MBF/mg S, the $S^{0}$ flocculation capacity of $\mathrm{MBF}$ remained stable. These results indicated that 
excessive flocculant doses resulted in colloidal restabilization, while low doses were insufficient for destabilizing the aggregates in most of the biogenic $\mathrm{S}^{0}$ colloids in the effluent, and the both excessive and low doses resulted in low flocculation rates.

Turbidity depends on the degree of water purification and is an important index for evaluating the effects of biogenic sulfur flocculation. The turbidity removal showed trends similar to those of $\mathrm{S}^{0}$ flocculation (Fig. 2). The turbidity decreased as the PAC dose increased to 1.3-1.5 mg PAC/mg S and increased when greater PAC doses were used. Maximum turbidity removal occurred at 2.3-2.8 $\mathrm{mg}$ PAC/mg S, which corresponded to a turbidity removal of approximately $82 \%-88 \%$, and then decreased as the PAC dosage increased. The removal of turbidity did not significantly change as the MBF dose increased and fluctuated between approximately 30\%-46\% (Fig. 2). Meanwhile, the removal rate of turbidity fluctuated between approximately $21 \%$ and $36 \%$ as the PAM dose increased from 1.3 to $3.3 \mathrm{mg} \mathrm{PAM} / \mathrm{mg}$ S. When the turbidity removal plateaued, the flocculant dose was approximately the same as that during maximum $\mathrm{S}^{0}$ flocculation.

Fig. 2 shows that optimum $S^{0}$ biogenic flocculation points were observed when using PAC, PAM and MBF. The optimum dose could be obtained by parsing the flocculation curves in Design Expert 8.0.1. The predicted optimal doses and experimental validation results are shown in Table 4. As shown in Table 4, the experimental values of the $\mathrm{S}^{0}$ flocculation rate reached $86.43 \%, 13.14 \%$ and $77.90 \%$ at $2.42 \mathrm{mg} \mathrm{PAC} / \mathrm{mg} \mathrm{S}, 2.75$ $\mathrm{mg} \mathrm{PAM} / \mathrm{mg} \mathrm{S}$ and $2.38 \mathrm{mg} \mathrm{MBF} / \mathrm{mg} \mathrm{S}$, respectively.

In the flocculation process, the flocculant was used to agglomerate the destabilized colloidal particles into large particles and then precipitates (Wang et al., 2011). The major mechanisms of flocculation of PAC were surface-charge neutralization and bridging (Gregory, 1996). For PAC, surface-charge neutralization occurred because its charge was opposite in sign to $\mathrm{S}^{0}$, which result in aggregation caused by specific ion absorption. For PAM, the most important mechanism of flocculation is the polymer bridging, which occurs because segments of a polymer chain get absorbed on various particles, thus linking the 
particles together (Tripathy et al., 2001). Usually, PAM has good adsorption effect on the small destablized flocs because of the carboxylic functional groups and the molecular chains. But due to its microsize and zeta potential $(-19.6 \pm 1.4 \mathrm{mV})$, biogenic $\mathrm{S}^{0}$ exhibits colloidal properties, hampering its adsorption with PAM. The single PAM had low efficiency in $S^{0}$ removal because there is litter charge on its polymer to aggregate the suspension during the process of flocculation (Zhang et al., 2004) and the adsorption capacity of PAM is not enough to destablize the colloid system. For MBF, the adsorption bridging and compressing the electric double layer played the leading role in the flocculation process (Wang, et al., 2015). Meanwhile, the net-catch of MBF can promote the $S^{0}$ flocculation. As a result, PAC were more effective as flocculating agents for destabilizing and sedimenting colloidal $\mathrm{S}^{0}$.

\subsection{RSM approach for optimizing the flocculation conditions}

\subsubsection{Model building and data analysis}

In this study, two parameters ( $\mathrm{pH}$ and mixing speed) were studied using a CCD model with two levels (the minimum and maximum). As shown in Table 3 , the $S^{0}$ flocculation rate by PAC, PAM and MBF fluctuated between 21.5\%-96.7\%, 3.2\%-15.5\% and $15.9 \%-73.1 \%$, respectively, in the tested $\mathrm{pH}$ and stirring intensity ranges. Meanwhile, $91.7 \%-96.7 \%, 14.8 \%-15.5 \%$ and $69.2 \%-73.1 \% \mathrm{~S}^{0}$ flocculation rates were obtained at $\mathrm{pH}$ 6 and at a stirring speed of $120 \mathrm{r} / \mathrm{min}$ in the PAC, PAM and MBF case, respectively. These data show that the interactions between $\mathrm{pH}$ and the stirring intensity affected $\mathrm{S}^{0}$ flocculation. Statistical analysis of the experimental data is necessary to establish optimal

$\mathrm{S}^{0}$ flocculation conditions in the range of the studied variables. The experimental results were evaluated, and quadratic models of the PAC and MBF flocculation capacities for $\mathrm{S}^{0}$ were obtained using Eqs. (4)-(5), respectively.

$$
\begin{aligned}
& y_{1}=91.32-22.77 A+8.98 B-28.71 A^{2}-26.56 B^{2} \\
& y_{2}=14.67-1.92 A+1.87 B-0.67 A B-5.65 A^{2}-4.00 B^{2}
\end{aligned}
$$


$y_{3}=69.93-12.57 A+5.60 B-3.02 A B-21.06 A^{2}-24.96 B^{2}$

In Eqs. (4)-(5), $y_{1}, y_{2}$ and $y_{3}$ are the $S^{0}$ flocculation rates following the addition of different PAC, PAM and MBF doses, respectively, and $A$ and $B$ correspond to the independent variables ( $\mathrm{pH}$ and stirring intensity).

As shown in Table 5, when "Prob > F" is less than 0.0500, the model terms are significant. In PAC case and in MBF case, the values of $A, A^{2}$, and $B^{2}$ were significant model terms. In PAM case, $A, B, A^{2}, B^{2}$ are significant model terms. The normal probability and studentized residual plots are shown in Fig. 4 for the flocculation of $S^{0}$ by PAC, PAM and MBF, respectively. The $R^{2}$ value (PAC, 93\%; PAM, 96\%; MBF, 95\%) indicates that the model could explain the majority of the total variations. The experimental values correspond well with the predicted values for PAC, PAM and MBF. The statistical analysis results showed that these quadratic models could be used to navigate the design space.

\subsubsection{Mutual parameter effects}

A response surface plot was used to determine $\mathrm{S}^{0}$ flocculation by PAC, PAM and MBF over interactive variables $\mathrm{pH}$ and stirring intensity (Fig. 5). The two dimensional contour plots are shown in Fig. 6. As shown in Fig. 5, the flocculation of $S^{0}$ increased in the PAC case as the $\mathrm{pH}$ increased up to 4.6-4.9 and then decreased as the $\mathrm{pH}$ continued to increase. For PAM and MBF, maximum flocculation occurred at $\mathrm{pH}$ 5.3-5.6 and 5.0-5.2, respectively, and lower flocculation occurred at higher $\mathrm{pH}$ values, potentially due to the negative charge on the biogenic $S^{0}$ surface. The amount of positive charge needed to neutralize the negative charge of biogenic $\mathrm{S}^{0}$ at low $\mathrm{pH}$ is greater than that at high $\mathrm{pH}$. Meanwhile, $\mathrm{pH}$ is the most important factor that affects the Zeta potential, and the absolute value of the Zeta potential approaches zero as the $\mathrm{pH}$ decreases, making the colloid dispersed system unstable (Hunter, 2013). The acidic condition was in favor of the improvement of cationic charge density as well as the extension of the grafting chain 
in the solution (Wang et al., 2011). Both the charge neutralization ability and the sweep-floc ability were enhanced in this case. Taking the two factors into account together, acidic condition was appropriate for the biogenic $S^{0}$ flocculation.

Fig. 5 also shows the effects of stirring intensity on flocculation. Mixing during the flocculation process provides close encounters between the particles and flocculating agents (Chen et al., 1998). To achieve a high flocculation rate, the effects of high and low mixing speeds on biogenic $S^{0}$ flocculation were investigated. As shown in Fig. 5, the flocculation resulting from PAC and PAM increased as the mixing speed increased to $120-130 \mathrm{r} / \mathrm{min}$, and then slightly decreased. In the MBF case, the biogenic $\mathrm{S}^{0}$ flocculation rate sharply increased with increasing stirring intensity. The maximum flocculation rate observed at 120-130 r/min was 70\%-75\%. When the stirring intensity was between 80 and $120 \mathrm{r} / \mathrm{min}$, the $S^{0}$ flocculation results indicated that the flocculation rate increased as the mixing speed increased, which provided more opportunities for contact between the $\mathrm{S}^{0}$ and flocculants to allow for aggregation and to increase the flocculation rate. However, floccules are easily destroyed when mixing speeds are too fast. Thus, the flocculation rate decreased as the mixing speeds increased beyond $120 \mathrm{r} / \mathrm{min}$.

\subsubsection{Optimization analysis and model validation}

Optimum factor levels were obtained by analyzing the response surface contour and derivatives of the equation of the above model. According to the results shown in the contour plot (Fig. 6), relatively high $\mathrm{S}^{0}$ flocculation rates of $97.12 \%, 15.08 \%$ and $72.23 \%$ were predicted at $\mathrm{pH} 4.73$ and $128.85 \mathrm{r} / \mathrm{min}$ in the PAC case, $\mathrm{pH} 5.45$ and $129.96 \mathrm{r} / \mathrm{min}$ in the PAM case and $\mathrm{pH} 5.08$ and $125.25 \mathrm{r} / \mathrm{min}$ in the MBF case, respectively.

Verification tests were performed using the predicted optimal parameters, and the results are summarized in Table 6. As shown in Table 6, at $\mathrm{pH} 4.73$ and $129 \mathrm{r} / \mathrm{min}$, the experimental value of the $\mathrm{S}^{0}$ flocculation rate reached $97.53 \%$ when $2.42 \mathrm{mg}$ PAC/mg S was added. At pH 5.45 and $130 \mathrm{r} / \mathrm{min}$, the experimental value of the $\mathrm{S}^{0}$ flocculation rate 
reached $15.41 \%$ when $2.75 \mathrm{mg} \mathrm{PAC} / \mathrm{mg} \mathrm{S}$ was added. At $\mathrm{pH} 5.08$ and $125 \mathrm{r} / \mathrm{min}$, the experimental value of the $S^{0}$ flocculation rate reached $71.98 \%$ when $2.38 \mathrm{mg} \mathrm{MBF} / \mathrm{mg} \mathrm{S}$ was added. The $S^{0}$ flocculation rates obtained from experimentation were very similar to those estimated using the quadratic model. Consequently, the RSM approach was successfully applied to model and optimize the biogenic $S^{0}$ flocculation process.

\section{Conclusions}

This study successfully compared the PAC, PAM and MBF performances for biogenic $\mathrm{S}^{0}$ flocculation and established optimum operating parameters for sulfur recovery. The effects of flocculant dose on biogenic $S^{0}$ flocculation indicated optimal doses of $2.42 \mathrm{mg}$ PAC/mg S, $2.75 \mathrm{mg}$ PAM/mg S and $2.38 \mathrm{mg} \mathrm{MBF} / \mathrm{mg} \mathrm{S}$, with $\mathrm{S}^{0}$ flocculation rates reaching up to $86.78 \%, 13.37 \%$ and $78.27 \%$, respectively. Based on the RSM approach, which uses CCD for experimental design, and the fitness of the polynomial equation, the optimal $\mathrm{S}^{0}$ flocculation conditions occurred under conditions of $\mathrm{pH} 4.73,129 \mathrm{r} / \mathrm{min}$ and $2.42 \mathrm{mg} \mathrm{PAC} / \mathrm{mg} \mathrm{S}$. Under these conditions, the predicted and actual flocculation efficiencies reached $97.12 \%$ and $97.53 \%$, respectively, in the presence of PAC.

\section{Acknowledgments}

This work was supported by the National High-Tech Research and Development Program (863) of China (No. 2011AA060904), the National Science Foundation for Distinguished Young Scholars (No. 51225802), the Science Fund for Creative Research Groups of the National Natural Science Foundation of China (No. 51121062), the National Key Technology Research and Development Program of the Ministry of Science and Technology of China (No. 2010BAC67B02), the Fundamental Research Funds for Central Universities (No. AUGA5710055514) and the National Natural Science Foundation of China (Nos. 51176037, 51308147, 51308147 and 51408591). 


\section{References}

Aljuboori, A.H.R., Idris, A., Abdullah, N., Mohamad, R., 2013. Production and characterizationof a bioflocculant produced by Aspergillus flavus. Bioresour. Technol. 127, 489-493.

Aljuboori, A.H.R., Uemura, Y., Osman, N.B., Yusup, S., 2014. Production of a bioflocculant from Aspergillus niger using palm oil mill effluent as carbon source. Bioresour. Technol. 171, 66-70.

Beristain-Cardoso, R., Texier, A.C., Sierra-Álvarez, R., Field, J.A., Razo-Flores, E., Gomez, J., 2008. Simultaneous sulfide and acetate oxidation under denitrifying conditions using an inverse fluidized bed reactor. J. Chem. Technol. Biotechnol. 83(9), 1197-1203.

Bezawada, J., Hoang, N.V., More, T.T., Yan, S., Tyagi, N., Tyagi, R.D., et al., 2013. Production of extracellular polymeric substances (EPS) by Serratia sp.1 using wastewater sludge as raw material and flocculation activity of the EPS produced. J. Environ. Manag. 128, 83-91.

Cao, C.R., Ke, J.M., Cui, G.F., Wang, K.J., 2002. Biological flue gas de-sulfurization technology in Netherlands. Foreign Sci. Technol. China. 5, 38-39

Celis-García, L.B., González-Blanco, G., Meraz, M., 2008. Removal of sulfur inorganic compounds by a biofilm of sulfate reducing and sulfide oxidizing bacteria in a down- flow fluidized bed reactor. J. Chem. Technol. Biotechnol. 83(3), 260-268.

Chen, L.A., Serad, G.A., Carbonell, R.G., 1998. Effect of mixing conditions on flocculation kinetics of wastewaters containing proteins and other biological compounds using fibrous materials and polyelectrolytes. Braz. J. Chem. Eng. 15(4), $358-368$.

Chen, C., Ren, N, Wang, A., Yu, Z., Lee, D.J., 2008. Microbial community of granules in expanded granular sludge bed reactor for simultaneous biological removal of sulfate, nitrate and lactate. Appl. Microbial. Biotechnol. 79(6), 1071-1077. 
Córdova, F.C., León, A.G., Reyes, R.G., González, M.G., Regalado, E.S., González, M.S., et al., 2011. Response surface methodology for lead biosorption on Aspergillus terreus. Int. J. Environ. Sci. Te. 8(4), 695-704.

Fortuny, M., Guisasola, A., Casas, C., Gamisans, X., Lafuente, J., Gabriel, D., 2010. Oxidation of biologically produced elemental sulfur under neutrophilic conditions. J. Chem. Technol. Biotechnol. 85(3), 378-386.

Gregory, J., 1996. Industrial Water Soluble Polymers. The Royal Society of Chemistry, Cambridge, UK.

Hao, X.D., Dai, J., Wei, L., 2006. Theoretical and technical progresses of biological sulfur removal. Ecol. Environ. China. 15(4), 844-853.

Hunter, R.J., 2013. Zeta potential in colloid science: principles and applications (Vol. 2). Academic Press, New York, USA.

Jadhav, M.V., Mahajan, Y.S., 2014. Application of response surface methodology to water/wastewater treatment using Coccinia indica. Desalin. Water Treat. 52(34-36), 6403-6411.

Janssen, A., De Keizer, A., Van Aelst, A., Fokkink, R., Yangling, H., Lettinga, G., 1996. Surface characteristics and aggregation of microbiologically produced sulphur particles in relation to the process conditions. Colloid. Surface. B. 6(2), 115-129.

Janssen, A.J.H., De Keizer, A., Lettinga, G., 1994. Colloidal properties of a microbiologically produced sulphur suspension in comparison to a LaMer sulphur sol. Colloid. Surface. B. 3(1), 111-117.

Jiang, G., Sharma, K. R., Guisasola, A., Keller, J., Yuan, Z., 2009. Sulfur transformation in rising main sewers receiving nitrate dosage. Water. Res. 43(17), $4430-4440$.

Kiran, B., Thanasekaran, K., 2011. Copper biosorption on Lyngbya putealis: application of response surface methodology (RSM). Int. Biodeter. Biodegr. 65(6), 840-845. 
Knobel, A.N., Lewis, A.E., 2002. A mathematical model of a high sulphate wastewater anaerobic treatment system. Water Res. 36(1), 257-265.

Li, Y.W., Xie, Q.L., Zhang, P., 2006. New Techniques for the Treatment of Molasses Distillery Wastewater. Guangzhou Environ. Sci. China. 3, 003.

Li, Y.X., Su, B.Q., Geng, Z.Y., Yao, B.B., Chi, Y.Z., 2000. Biological treatment of acidic wastewater containing sulfate and recovery of elementary sulfur. Water Wastewater Eng. 26, 28-30.

More, T.T., Yadav, J.S.S., Yan, S., Tyagi, R.D., Surampalli, R.Y., 2014. Extracellular polymeric substances of bacteria and their potential environmental applications. J. Environ. Manag. 144, 1-25.

Özer, A., Gürbüz, G., Çalimli, A., Körbahti, B.K., 2008. Investigation of nickel(II) biosorption on Enteromorpha prolifera: optimization using response surface analysis. J. Hazard. Mater. 152(2), 778-788.

Prazeres, A.R., Carvalho, F., Rivas, J., 2013. Fenton-like application to pretreated cheese whey wastewater. J. Environ. Manag. 129, 199-205.

Riaño, B., García-González, M.C., 2014. On-farm treatment of swine manure based on solid-liquid separation and biological nitrification-denitrification of the liquid fraction. J. Environ. Manag. 132, 87-93.

Sahinkaya, E., Hasar, H., Kaksonen, A.H., Rittmann, B.E., 2011. Performance of a sulfide-oxidizing, sulfur-producing membrane biofilm reactor treating sulfide-containing bioreactor effluent. Environ. Sci. Technol. 45(9), 4080-4087.

Schlegel, H.G., 1989. Allgemline Mikrobiologie ( fifth ed). Thieme, Stuttgart, Germany.

Tripathy, T., Karmakar, N.C., Singh, R.P., 2001. Development of novel polymeric flocculant based on grafted sodium alginate for the treatment of coal mine wastewater. J. Appl. Polym. Sci. 82(2), 375-382. 
Wang, A.J., Du, D.Z., Ren, N.Q., Van Groenestijn, J.W., 2005. An innovative process of simultaneous desulfurization and denitrification by Thiobacillus denitrificans. J. Environ. Sci. Heal. 40(10), 1939-1949.

Wang, Z., Shen, L., Zhuang, X.L., Shi, J.S., Wang, Y.P., He, N., 2015. Flocculation Characterization of a Bioflocculant fromBacillus licheniformis. Ind. Eng. Chem. Res. 54(11), 2894-2901.

Wang, J.P., Chen, Y.Z., Wang, Y., Yuan, S.J., Yu, H.Q., 2011. Optimization of the coagulation-flocculation process for pulp mill wastewater treatment using a combination of uniform design and response surface methodology. Water Res. 45(17), 5633-5640.

Yuan, Y., Chen, C., Liang, B., Huang, C., Zhao, Y., Xu, X. et al., 2014b. Fine-tuning key parameters of an integrated reactor system for the simultaneous removal of COD, sulfate and ammonium and elemental sulfur reclamation. J. Hazard. Mater. 269, $56-67$.

Yuan, Y., Wang, A., Ma, S., Chen C., Zhao Y., Tan W. et al., 2014a. Distribution characteristics and separation of biological sulfur in denitrifying sulfide removal process. J. Harbin Institute of Technol. China. 46(8), 34-39.

Zhang, K.S., Zhou, Q.X., Xiao, H., 2004. Flocculation performance of a novel synthesized flocculant with low ecological risk. J. Environ. Sci. 16(3), 443-446.

Zheng, H., Ma, J., Zhai, J., Zhu, C., Tang, X., Liao, Y., et al., 2014. Optimization of flocculation process by response surface methodology for diethyl phthalate removal using anionic polyacrylamide. Desalin. Water Treat. 52(28-30), 5390-5400.

Zhu, Y.B., Ma, F., Huang, J.L., Liu, Y.H., 2006. Study on flocculation properties of bioflocculant and optimization of flocculation conditions. China Water \& Wastewater. 22(3), 4-8. 


\section{List of tables}

Table 1 Experimental design and flocculant dose optimization results

Table 2 Experimental factor levels used in the factorial design

Table 3 Experimental design and biogenic $S^{0}$ flocculation parameter results

Table 4 The predicted optimal dose and verification results

Table 5 ANOVA results of the quadratic models for biogenic $\mathrm{S}^{0}$ flocculation

Table 6 The predicted optimal parameters and verification results

\section{List of figures}

Fig. $1 S^{0}$-containing effluent

Fig. 2 The effects of dosage on biogenic sulfur flocculation and turbidity removal

Fig. 3 The studentized residuals and normal probability plot for the effects of flocculant dose on biogenic $\mathrm{S}^{0}$ flocculation

Fig. 4 The studentized residuals and normal probability plot for optimizing the biogenic $S^{0}$ flocculation conditions

Fig. 5 Effect of the interaction between $\mathrm{pH}$ and stirring intensity on biogenic $\mathrm{S}^{0}$ flocculation Fig. 6 Two-dimensional contour plot for biogenic $S^{0}$ flocculation 


\section{JES-D-15-00867- tables}

Table 1 Experimental design and flocculant dose optimization results

\begin{tabular}{|c|c|c|c|c|c|c|c|}
\hline \multirow{2}{*}{$\begin{array}{l}\text { Experimental } \\
\text { run }\end{array}$} & \multirow{2}{*}{$\begin{array}{l}\text { Flocculant dose } \\
(\mathrm{mg} \text { flocculant/mg S) }\end{array}$} & \multicolumn{3}{|c|}{$\begin{array}{l}\text { Biogenic } S^{0} \text { flocculation rate } \\
(\%)\end{array}$} & \multicolumn{3}{|c|}{ Turbidity removal (\%) } \\
\hline & & $\mathrm{PAC}$ & PAM & MBF & PAC & PAM & MBF \\
\hline 1 & $2.80(05)$. & 81 & 14 & 76 & 82 & 23 & 40 \\
\hline 2 & $3.30(1.0)$ & 75 & 11 & 67 & 70 & 28 & 43 \\
\hline 3 & $2.30(0.0)$ & 86 & 13 & 75 & 88 & 35 & 48 \\
\hline 4 & $3.30(1.0)$ & 77 & 12 & 69 & 71 & 27 & 44 \\
\hline 5 & $1.30(-1.0)$ & 63 & 2 & 6 & 45 & 18 & 30 \\
\hline 6 & $1.30(-1.0)$ & 64 & 3 & 8 & 46 & 22 & 32 \\
\hline 7 & $1.80(-0.5)$ & 70 & 7 & 64 & 53 & 36 & 46 \\
\hline
\end{tabular}

PAC: polyaluminum chloride; PAM: polyacrylamide; MBF: microbial flocculant.

Table 2 Experimental factor levels used in the factorial design

\begin{tabular}{llllll}
\hline Factor & Code & Units & Low & Central value & High \\
\hline $\mathrm{pH}$ & $A$ & & $-1(3.5)$ & $0(5.25)$ & $1(7)$ \\
Stirring intensity & $B$ & $\mathrm{r} / \mathrm{min}$ & $-1(80)$ & $0(120)$ & $1(160)$ \\
\hline
\end{tabular}

Table 3 Experimental design and biogenic $S^{0}$ flocculation parameter results

\begin{tabular}{|c|c|c|c|c|c|c|c|c|}
\hline \multirow{2}{*}{ Run } & \multirow{2}{*}{$\mathrm{pH}$} & \multirow{2}{*}{$\begin{array}{l}\text { Stirring } \\
\text { intensity } \\
(\mathrm{r} / \mathrm{min})\end{array}$} & \multicolumn{3}{|c|}{ Biogenic $\mathrm{S}^{0}$ flocculation rate (\%) } & \multicolumn{3}{|c|}{ Turbidity removal (\%) } \\
\hline & & & PAC & PAM & MBF & PAC & PAM & MBF \\
\hline 1 & 3 & 80 & 44.2 & 5.3 & 26.7 & 43.4 & 14.6 & 26.3 \\
\hline 2 & 9 & 80 & 20.6 & 3.2 & 15.9 & 19.8 & 10.6 & 16.1 \\
\hline 3 & 3 & 160 & 71.5 & 9.1 & 41.5 & 68.1 & 16.4 & 44.9 \\
\hline 4 & 9 & 160 & 21.5 & 4.3 & 18.6 & 23.7 & 12.5 & 17.8 \\
\hline 5 & 3 & 120 & 87.3 & 10.4 & 66.2 & 85.2 & 18.5 & 61.4 \\
\hline 6 & 9 & 120 & 24.3 & 5.8 & 24.5 & 26.2 & 13.7 & 24.3 \\
\hline 7 & 6 & 80 & 45.1 & 6.6 & 33.4 & 46.0 & 16.2 & 27.8 \\
\hline
\end{tabular}




\begin{tabular}{lllllllll}
\hline 8 & 6 & 160 & 70.8 & 12.9 & 49.5 & 69.7 & 20.3 & 50.2 \\
9 & 6 & 120 & 91.7 & 14.8 & 73.1 & 94.3 & 34.8 & 69.3 \\
10 & 6 & 120 & 95.8 & 15.1 & 69.2 & 93.5 & 33.9 & 64.7 \\
11 & 6 & 120 & 93.4 & 14.6 & 70.8 & 91.6 & 35.6 & 68.5 \\
12 & 6 & 120 & 96.7 & 15.5 & 72.4 & 98.4 & 37.7 & 67.8 \\
13 & 6 & 120 & 92.6 & 15.2 & 71.2 & 95.8 & 36.4 & 69.4 \\
\hline
\end{tabular}

Table 4 The predicted optimal dose and verification results

\begin{tabular}{llll}
\hline Solution & Dose & \multicolumn{2}{l}{ Biogenic S $\mathrm{S}^{0}$ flocculation rate } \\
\cline { 3 - 4 } & & Prediction (\%) & Validation (\%) \\
\hline $\mathrm{PAC}$ & $2.42 \mathrm{mg} \mathrm{PAC} / \mathrm{mg} \mathrm{S}$ & 86.78 & 86.43 \\
$\mathrm{PAM}$ & $2.75 \mathrm{mg} \mathrm{PAM} / \mathrm{mg} \mathrm{S}$ & 13.37 & 13.14 \\
$\mathrm{MBF}$ & $2.38 \mathrm{mg} \mathrm{MBF} / \mathrm{mg} \mathrm{S}$ & 78.27 & 77.90 \\
\hline
\end{tabular}

Table 5 ANOVA results of the quadratic models for biogenic $\mathrm{S}^{0}$ flocculation

\begin{tabular}{|c|c|c|c|c|c|c|c|}
\hline Source & Solution & Model & $A-\mathrm{pH}$ & $\begin{array}{l}B \text {-Stirring } \\
\text { intensity }\end{array}$ & $A B$ & $A^{2}$ & $B^{2}$ \\
\hline \multirow{3}{*}{$\begin{array}{l}\text { Sum } \\
\text { Squares }\end{array}$} & PAC & 10587.65 & 3109.927 & 484.2017 & 174.24 & 2276.594 & 1948.391 \\
\hline & PAM & 255.5252 & 22.04167 & 20.90667 & 1.8225 & 88.27456 & 44.2667 \\
\hline & MBF & 5911.346 & 947.5267 & 188.16 & 36.6025 & 1224.809 & 1720.481 \\
\hline \multicolumn{2}{|l|}{$\mathrm{d} f$} & 5 & 1 & 1 & 1 & 1 & 1 \\
\hline \multirow{3}{*}{$\begin{array}{l}\text { Mean } \\
\text { Square }\end{array}$} & PAC & 2117.531 & 3109.927 & 484.2017 & 174.24 & 2276.594 & 1948.391 \\
\hline & PAM & 51.10503 & 22.04167 & 20.90667 & 1.8225 & 88.27456 & 44.2667 \\
\hline & MBF & 1182.269 & 947.5267 & 188.16 & 36.6025 & 1224.809 & 1720.481 \\
\hline \multirow{3}{*}{$F$ Value } & PAC & 26.44388 & 38.83698 & 6.046745 & 2.175921 & 28.43026 & 24.33164 \\
\hline & PAM & 33.21049 & 14.32373 & 13.58615 & 1.184348 & 57.36503 & 28.76662 \\
\hline & $\mathrm{MBF}$ & 27.14088 & 21.75199 & 4.319513 & 0.840269 & 28.11746 & 39.49639 \\
\hline \multirow{3}{*}{$\begin{array}{l}p \text {-value } \\
\text { Prob }>F\end{array}$} & PAC & 0.0002 & 0.0004 & 0.0435 & 0.1837 & 0.0011 & 0.0017 \\
\hline & PAM & $<0.0001$ & 0.0069 & 0.0078 & 0.3125 & 0.0001 & 0.0010 \\
\hline & $\mathrm{MBF}$ & 0.0002 & 0.0023 & 0.0763 & 0.3898 & 0.0011 & 0.0004 \\
\hline
\end{tabular}


Table 6 The predicted optimal parameters and verification results

\begin{tabular}{llll}
\hline Solutions & $\mathrm{pH}$ & Stirring intensity $(\mathrm{r} / \mathrm{min})$ & Biogenic $\mathrm{S}^{0}$ flocculation rate $(\%)$ \\
\hline PAC $\quad$ Predicted value & 4.73 & 128.85 & 97.12 \\
$\quad$ Experimental value & 4.73 & 129 & 97.53 \\
\hline PAM Predicted value & 5.45 & 129.96 & 15.08 \\
$\quad$ Experimental value & 5.45 & 130 & 15.41 \\
MBF Predicted value & 5.08 & 125.25 & 72.23 \\
$\quad$ Experimental value & 5.08 & 125 & 71.98 \\
\hline
\end{tabular}




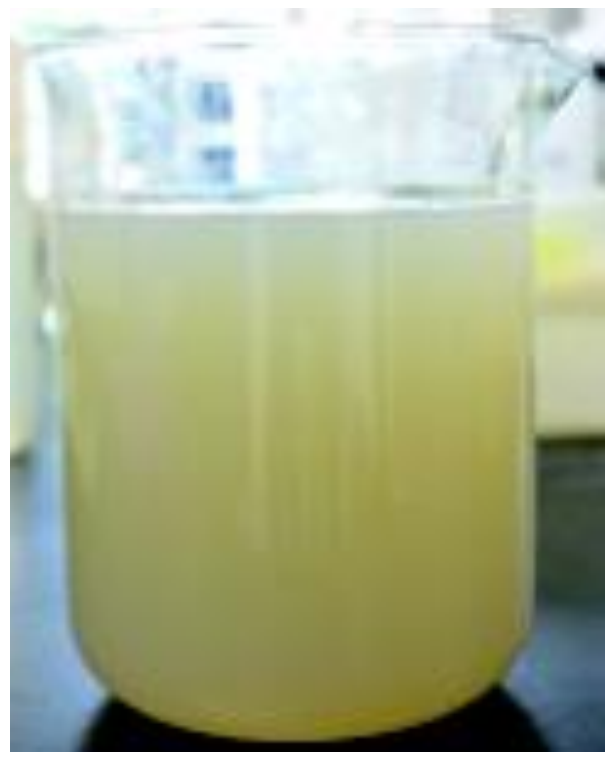



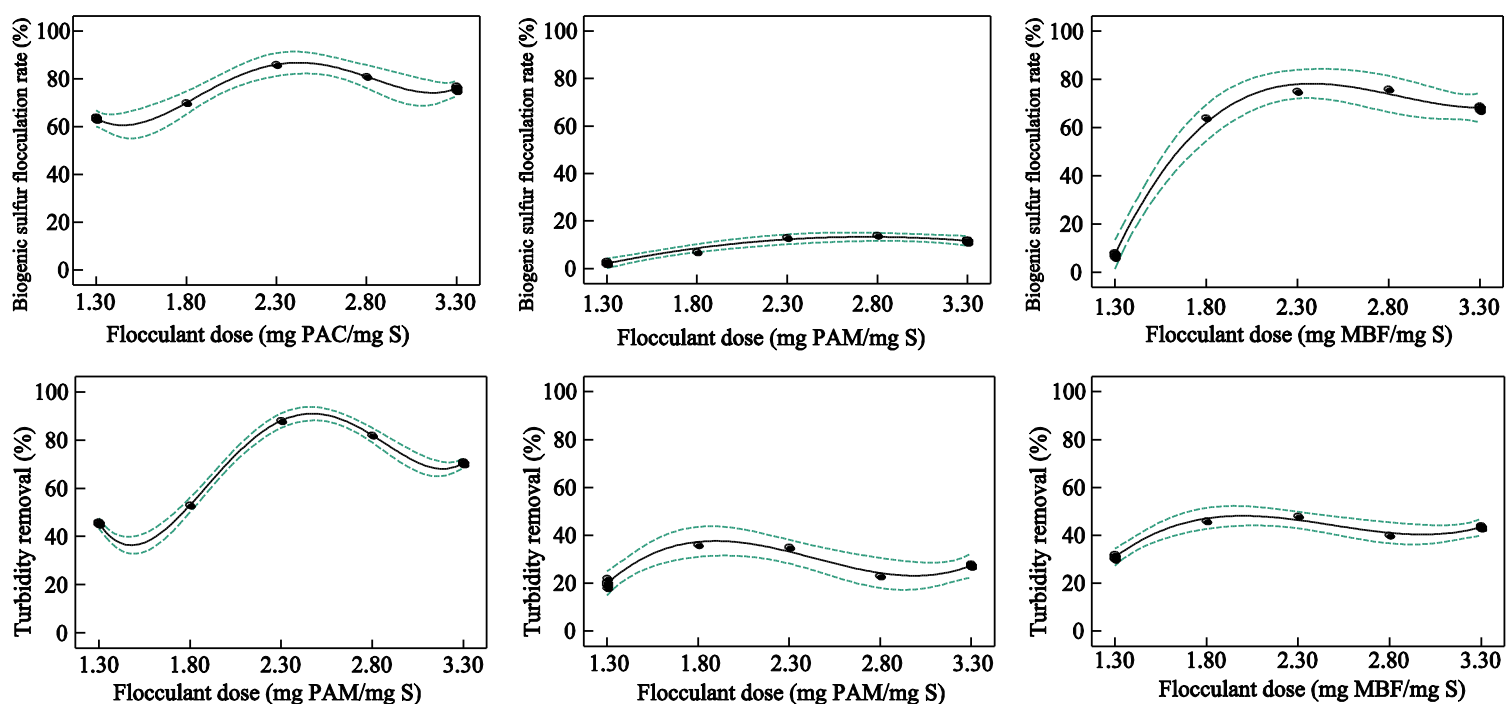

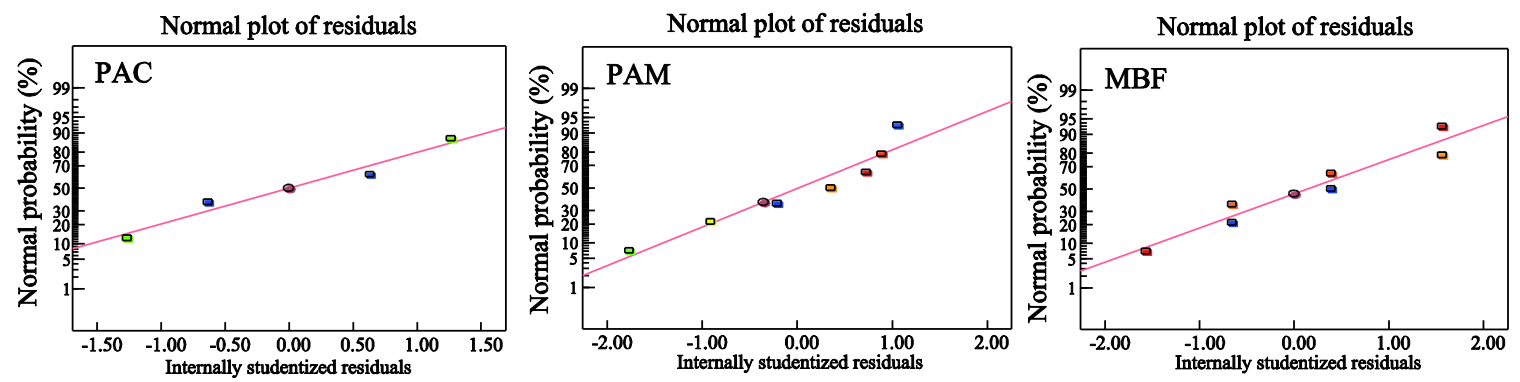

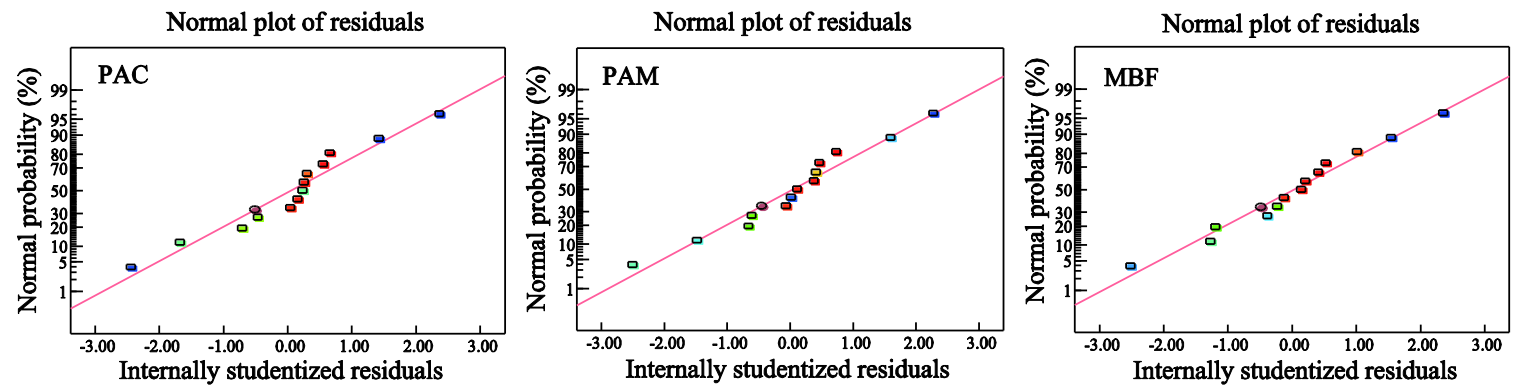

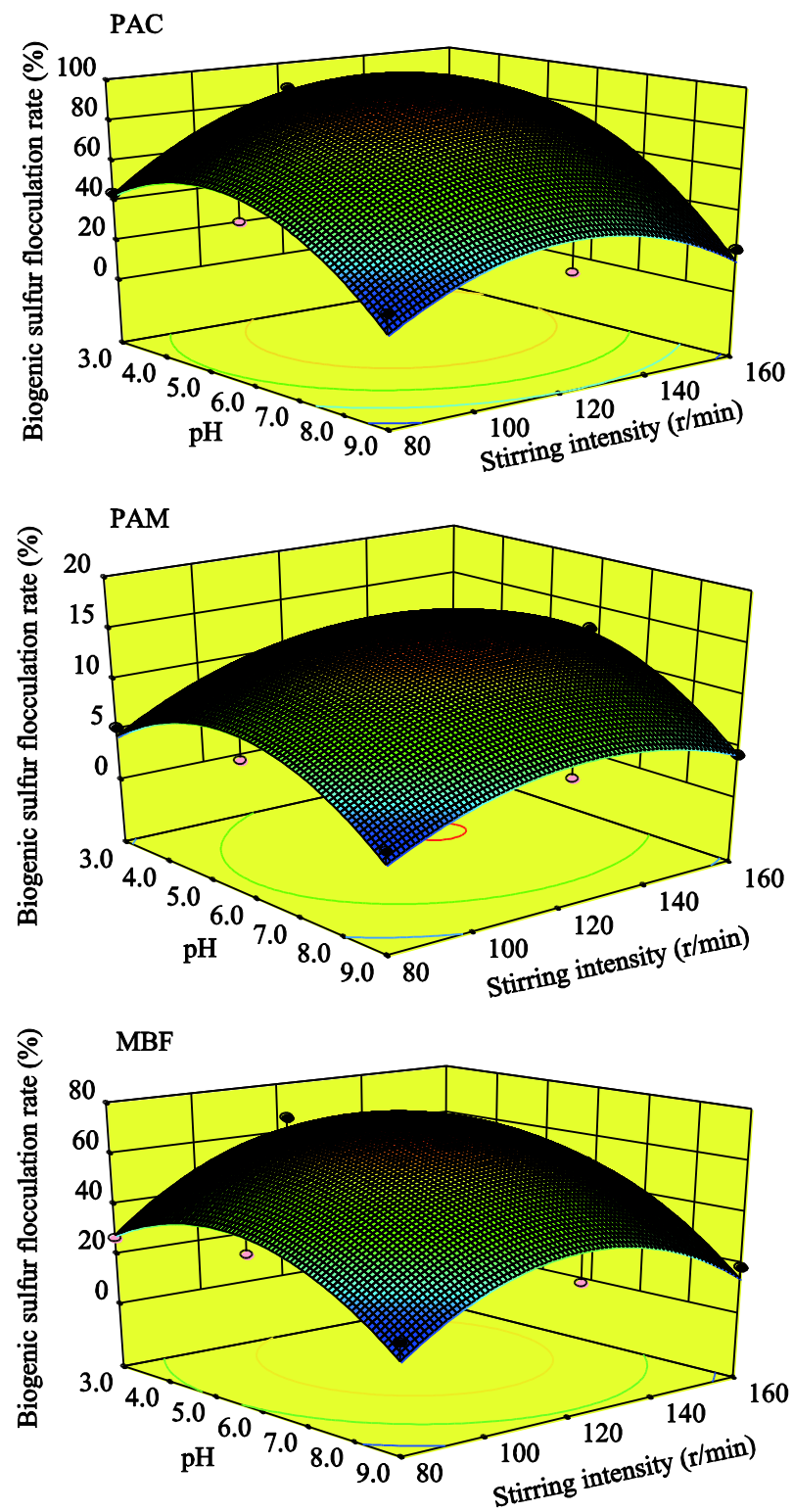

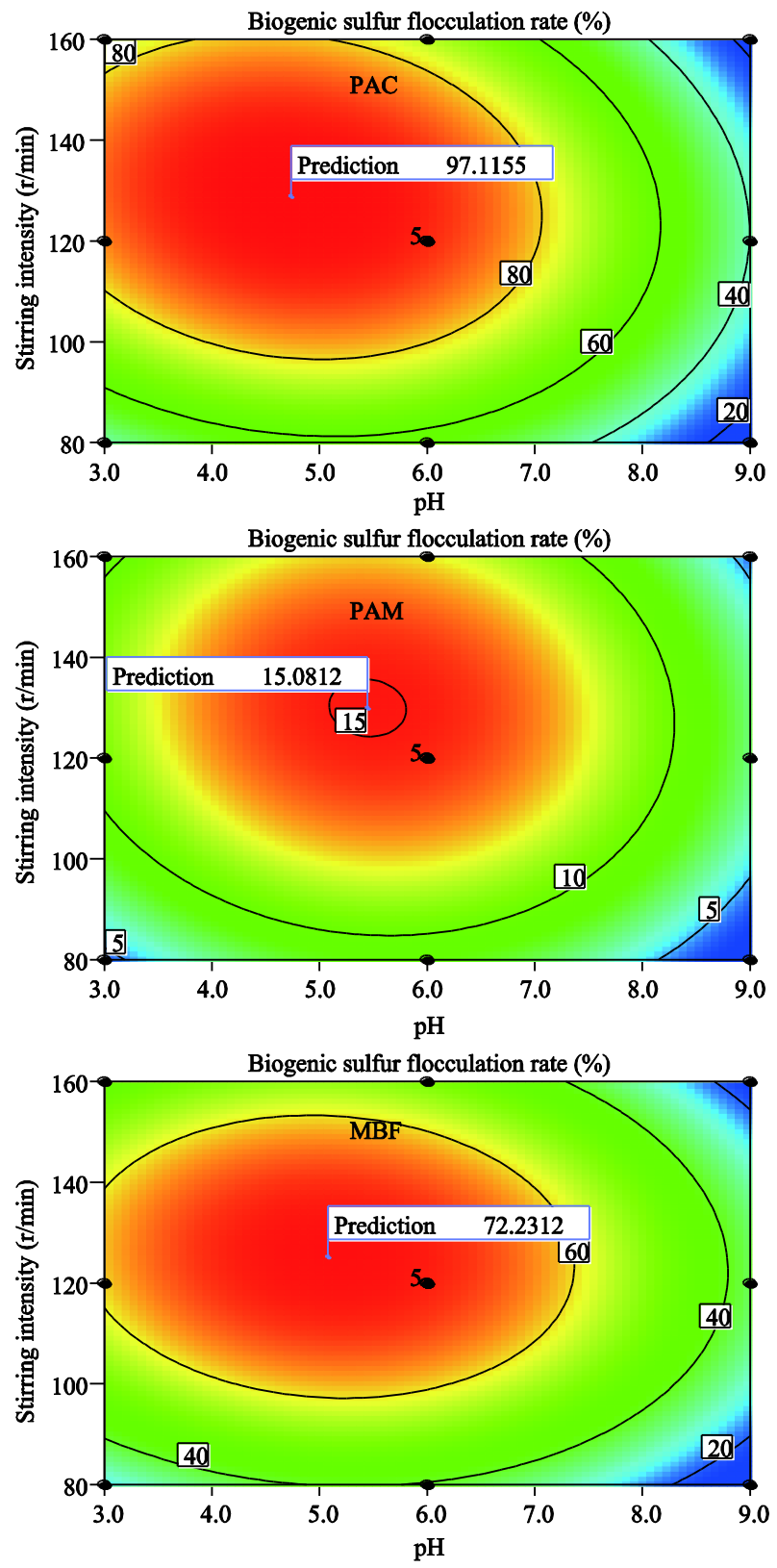


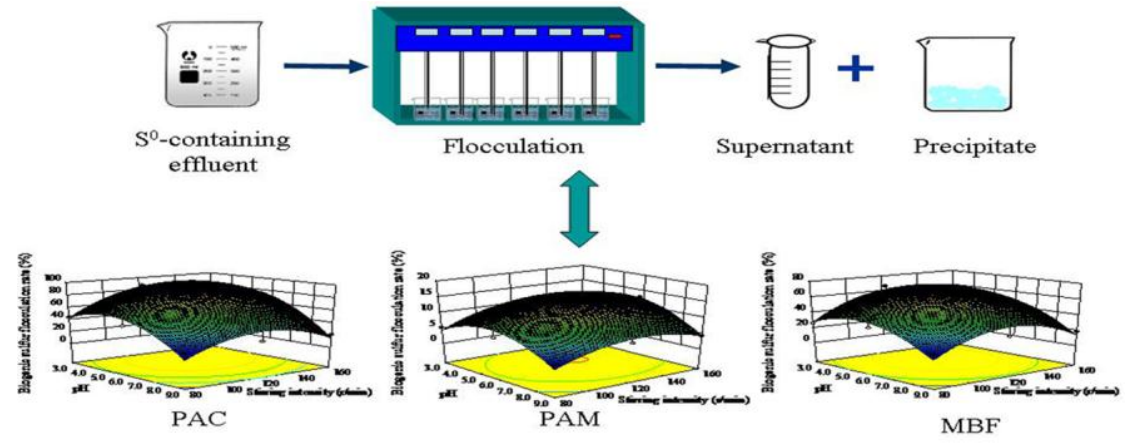

